\title{
A prática da governança em cooperativas: é possível fortalecer?
}

\author{
The practice of governance in cooperatives: is it possible to strengthen?
}

\author{
Bruna de Oliveira', Lucas José Guimarães" \\ ' Universidade Federal do Tocantins. brunadeoliveira@uft.edu.br \\ "Universidade Federal de Goiás - UFG. lucasjg@outlook.com
}

\section{RESUMO}

Diferente das organizações que visam a maximização dos retornos econômicos, as cooperativas, por meio da propriedade coletiva e gestão democrática, buscam a valorização do ser humano. Apesar dessas diferenças, como qualquer outra organização, as cooperativas precisam ser geridas. Para que os dirigentes eleitos pela Assembleia de cooperados conduzam o empreendimento para o sucesso, fazse necessária a adoção de ferramentas de gestão, como a implantação de boas práticas de governança. Tais práticas estão alicerçadas na transparência, prestação de contas, equidade e responsabilidade corporativa. Diante do exposto, esta investigação buscou examinar os resultados de um estudo que diagnosticou os desafios à implantação de um modelo de governança na rede de cooperativas da Unimed. Esta é uma pesquisa explicativa, que se guia por uma abordagem qualitativa. Os resultados revelam que as práticas de governança na rede de cooperativas da Unimed estão em seu estágio inicial, porém verificou-se que o processo de disseminação tem acontecido. $O$ principal desafio reside no seguimento de princípios como a participação, que estão que é fator chave na governança e está na base da própria doutrina cooperativista.

Palavras-chave: práticas de governança; cooperativas; unimed.

\section{ABSTRACT}

Unlike organizations that aim to maximize economic returns, cooperatives, through collective ownership and democratic management, seek to value the human being. Despite these differences, like any other organization, cooperatives need to be managed. For the directors elected by the Assembly of cooperative members to lead the enterprise to success, it is necessary to adopt management tools, such as the implementation of good governance practices. Such practices are 
based on transparency, accountability, equity and corporate responsibility. In view of the above, this investigation sought to examine the results of a study that diagnosed the challenges to the implementation of a governance model in the Unimed cooperative network. This is an explanatory research, guided by a qualitative approach. The results reveal that the governance practices in Unimed's cooperative network are in their initial stages, but it has been found that the dissemination process has taken place. The main challenge lies in following principles such as participation, which are a key factor in governance and are at the basis of the cooperative doctrine itself.

Keywords: governance practices; cooperatives; unimed.

\section{INTRODUÇÃO}

As cooperativas surgiram como alternativa à exploração do sistema capitalista. No Brasil, esses empreendimentos, baseados na propriedade coletiva e gestão democrática, tem significativa participação econômica e geram impactos sociais positivos.

Diferentemente das empresas de mercado, as cooperativas buscam a satisfação das necessidades e não apenas o acumular de lucros. Nesses empreendimentos, há uma valorização do ser humano, além da preocupação com o bem estar da sociedade.

Apesar de diferentes, empresas de mercado e cooperativas precisam ser administradas, seja por uma pessoa ou um grupo. Nessa perspectiva, a adoção de mecanismos de gestão tende a contribuir para a manutenção e sustentabilidade desses negócios. Dentre as ferramentas recentemente criadas está a governança, um conjunto de práticas que tem demonstrado sua capacidade de melhorar o desempenho e garantir a sobrevivência das organizações.

A ideia da governança foi criada num contexto de incertezas e riscos. Por isso seus princípios alicerçam-se na transparência, equidade, prestação de contas e responsabilidade corporativa. A implantação dessa ferramenta em cooperativas 
surge como um possível caminho para a profissionalização da administração, daí sua relevância.

Diante do exposto, o presente estudo buscou examinar os resultados de um estudo que diagnosticou os desafios à implantação de um modelo de governança numa rede de cooperativas do ramo de saúde. Esta pesquisa se guia pela intenção de detectar as dificuldades e explorar possibilidades para o fortalecimento da governança nessa rede de cooperativas.

A importância deste trabalho justifica-se pela necessidade de se aprimorar os mecanismos de gestão dentro das cooperativas, para que estas consigam crescer economicamente, melhorar a qualidade de vida de seus cooperados e ser sustentável. O sucesso do cooperativismo reflete diretamente no desempenho econômico do país. Por isso, é importante aprofundar as investigações que ofereçam embasamento científico para a implantação de práticas que ampliem o desempenho da gestão e levem as cooperativas à prosperidade. Só assim os sete ramos do cooperativismo brasileiro continuarão contribuindo com a geração de empregos, inclusão de pessoas e melhoria do bem estar social.

\section{REFERENCIAL TEÓRICO}

\subsection{Cooperativas: surgimento, princípios e características}

No contexto do capitalismo, a maior parte das relações socioeconômicas acontecem por meio da competição. Tendemos a encarar esse sistema de acumulação como natural, pois está dominante a muito tempo. No entanto, conforme Marx (1988), esse tipo de relação econômica gera uma divisão de classes, deixando de um lado aqueles que detém os meios de produção, e do outro, aqueles que possuem apenas sua mão de obra. 
O cooperativismo surge no contexto da Revolução Industrial, como uma alternativa para aqueles que ficavam com as desvantagens do capitalismo. Na época, as fábricas ofereciam péssimas condições aos trabalhadores, com longas jornadas de trabalho em atividades de risco, má alimentação, além de baixos salários.

É diante desse cenário que nasceu a ideia de cooperação. Surgiu como necessidade, como meio de sobrevivência para aqueles grupos de pessoas que, na reciprocidade de seu trabalho, no conjunto de suas ideias e no esforço continuado de suas ações, realizavam seus propósitos e objetivos (OCB, 2020).

O cooperativismo corresponde a um modo de produzir coletivo, baseado na democracia, solidariedade, independência e autonomia. Fundamenta-se na união de pessoas e não no capital, visando às necessidades do grupo. Os empreendimentos que funcionam a partir desses valores, as chamadas cooperativas, buscam prosperidade conjunta e não individual.

De modo geral, nos empreendimentos baseados na cooperação, as pessoas se unem, de forma voluntária, para satisfazer as necessidades econômicas, sociais e culturais em comum, mediante uma empresa de propriedade conjunta e de gestão democrática, tendo como objetivo principal a prestação de serviço aos seus cooperados, valorizando acima do capital, a pessoa. Conforme já apresentado, é um tipo de organização diferente de outras mercantis, uma vez que procura a satisfação das necessidades e não apenas o acumular de lucros (ver Quadro 1) (ACl, 2004).

Quadro 1 - Diferença entre cooperativa e empresa não cooperativa

\section{Cooperativa}

Empresa não cooperativa

- Sociedade de pessoas

- Sociedade de capital

- Objetivo: prestação de serviços ao cooperado

- Objetivo: lucro 
- Retorna sobras aos cooperados

- Cada cooperado, um voto

- Conselho de Administração eleito em Assembleia Geral dos cooperados
- Distribui lucros aos capitalistas

- Quanto maior a participação do capital, maior o poder de voto
- Conselho de Administração definido pelos sócios majoritários

Fonte: OCB, 2020.

De acordo com a Organização das Cooperativas Brasileiras/OCB (2020), o cooperativismo é:

“Um modelo de negócios pautado pelo empreendedorismo

e pela participação democrática. Unir pessoas e compartilhar resultados. Esta é a proposta do movimento cooperativista. O que se busca é a prosperidade conjunta, o atendimento às necessidades do grupo, e não o individualismo. De forma particular, a prática cooperativista promove, simultaneamente, crescimento econômico e inclusão social.

... esse movimento socialmente responsável e sustentável mobiliza dezenas de milhões de brasileiros de todas as idades, gêneros, raças e credos, e tem um espaço expressivo na economia do país. Suas ações também são alicerçadas em valores éticos de honestidade, transparência, democracia e responsabilidade social" (OCB, 2020, p. 7).

Segundo Holyoake (2005), o surgimento da primeira cooperativa moderna ocorreu em dezembro de 1844, quando operários de uma tecelagem em Rochdale, na Inglaterra decidiram abrir seu próprio negócio, devido à insatisfação em relação às 
condições de trabalho como tecelões. Essa cooperativa, registrada como Sociedade dos Probos Pioneiros de Rochdale tinha como objetivo principal gerar trabalho e renda àqueles que eram explorados ou estavam desempregados.

A história nos conta que os tecelões de Rochdale trabalhavam de 17 a 18 horas por dia, moravam em casas sem o mínimo de conforto, pagavam muito caro pelo que comiam e vestiam e, por isso, eram muito pobres. Com o surgimento da máquina a vapor a situação veio a agravar, significando o desemprego para vários operários. Para Singer (2002), essa situação levou os operários a se unirem, com a finalidade de se protegerem contra o desemprego e se manterem vivos, através da organização de uma cooperativa que pudesse supri-los do básico para viver até conseguirem um novo emprego.

Em 1985 foi fundada a Aliança Cooperativa Internacional (ACI), com o propósito de ser a entidade representativa do movimento cooperativista em todo o mundo. Por meio de debates e discussões e congressos realizados pela $\mathrm{ACl}$, desde Rochdale os princípios passaram por mudanças, conforme apresenta o Quadro 2. 
Quadro 2 - Evolução dos princípios cooperativistas

\begin{tabular}{|c|c|c|c|}
\hline \multicolumn{4}{|c|}{ PRINCÍPIOS COOPERATIVISTAS } \\
\hline \multirow{2}{*}{$\begin{array}{l}\text { Estatuto de } 1844 \\
\text { (Rochdale) }\end{array}$} & \multicolumn{3}{|c|}{ Congressos da Aliança Cooperativa Internacional } \\
\hline & 1937 (Paris) $^{28}$ & 1966 (Viena) & 1995 (Manchester) \\
\hline $\begin{array}{l}\text { 1. Adesão Livre } \\
\text { 2. Gestão Democrática } \\
\text { 3. Retorno Pro Rata das } \\
\text { Operações }\end{array}$ & $\begin{array}{l}\text { a) Princípios Essenciais } \\
\text { de Fidelidade aos } \\
\text { Pioneiros } \\
\text { 1. Adesão Aberta }\end{array}$ & $\begin{array}{l}\text { 1. Adesão Livre } \\
\text { (inclusive neutralidade } \\
\text { política, religiosa, racial e } \\
\text { social) }\end{array}$ & $\begin{array}{l}\text { 1. Adesão Voluntária e } \\
\text { Livre } \\
\text { 2. Gestão Democrática } \\
\text { 3. Participação }\end{array}$ \\
\hline $\begin{array}{l}\text { 4. Juro Limitado ao } \\
\text { Capital Investido } \\
\text { 5. Vendas a Dinheiro } \\
\text { 6. Educação dos } \\
\text { Membros } \\
\text { 7. Cooperativização }\end{array}$ & $\begin{array}{l}\text { 2. Controle ou Gestão } \\
\text { Democrática } \\
\text { 3. Retorno Pro-rata das } \\
\text { Operações } \\
\text { 4. Juros Limitados ao } \\
\text { Capital }\end{array}$ & $\begin{array}{l}\text { 2. Gestão Democrática } \\
\text { 3. Distribuição das } \\
\text { Sobras: } \\
\text { a) ao desenvolvimento da } \\
\text { cooperativa; } \\
\text { b) aos serviços comuns; }\end{array}$ & $\begin{array}{l}\text { Econômica dos Sócios } \\
\text { 4. Autonomia e } \\
\text { Independência } \\
\text { 5. Educação, Formação e } \\
\text { Informação } \\
\text { 6. Intercooperação }\end{array}$ \\
\hline Global & $\begin{array}{l}\text { b) Métodos Essenciais de } \\
\text { Ação e Organização } \\
\text { 5. Compras e Vendas à } \\
\text { Vista } \\
\text { 6. Promoção da Educação } \\
\text { 7. Neutralidade Política e } \\
\text { Religiosa. }\end{array}$ & $\begin{array}{l}\text { c) aos associados pro-rata } \\
\text { das operações } \\
\text { 4. Taxa Limitada de Juros } \\
\text { ao Capital Social } \\
5 \text {. Constituição de um } \\
\text { fundo para a educação } \\
\text { dos associados e do } \\
\text { público em geral } \\
6 . \text { Ativa cooperação entre } \\
\text { as cooperativas em } \\
\text { âmbito local, nacional e } \\
\text { internacional }\end{array}$ & $\begin{array}{l}\text { 7. Preocupação com a } \\
\text { Comunidade }\end{array}$ \\
\hline
\end{tabular}

Fonte: Cançado e Gontijo, 2004.

De acordo com Cristofolini (2014), esses princípios são linhas que orientam a conduta dos cooperados nas organizações cooperativas. Cançado e Contijo (2004) ressaltam que tais regras expressam o ideário cooperativo e as mudanças contribuíram para reforçar a diferença entre as cooperativas e as empresas não cooperativas.

Atualmente, os princípios que regem o cooperativismo são: $1^{\circ}$ ) Adesão voluntária e livre, $2^{\circ}$ ) Gestão democrática, $3^{\circ}$ ) Participação econômica dos membros, $4^{\circ}$ ) Autonomia e independência, $5^{\circ}$ ) Educação, formação e informação, $6^{\circ}$ ) Intercooperação e $7^{\circ}$ Interesse pela comunidade (CANÇADO; GONTIJO, 2004). Nessa nova perspectiva, que demonstra uma reformulação do cooperativismo, as cooperativas se tornaram autônomas, independentes e responsáveis pela comunidade onde estão inseridas. 
O $1^{\circ}$ princípio postula que os empreendimentos cooperativistas são abertos a quem quiser participar. Portanto, todas as pessoas, podem fazer parte. Não há discriminação social, política, racial, religiosa ou de gênero. $O 2^{\circ}$ princípio apresenta que as cooperativas são controladas pelos próprios cooperados, que participam ativamente da formulação de suas políticas, assim como o processo de tomada de decisões (CANÇADO; GONTIJO, 2004).

O $3^{\circ}$ princípio aponta nas organizações baseadas na cooperação, os membros contribuem igualmente e controlam o capital democraticamente. O $4^{\circ}$ princípio revela que as cooperativas são organizações autônomas. De acordo com a Aliança Cooperativa Internacional (2004), esses empreendimentos só devem ser administrados por seus membros, pois só assim garantirão o poder de não serem dependentes.

"As cooperativas são organizações autônomas, de ajuda mútua, controladas pelos seus membros. Se estas firmarem acordos com outras organizações, incluindo instituições públicas, ou recorrerem a capital externo, devem fazê-lo em condições que assegurem o controle democrático pelos seus membros e mantenham a autonomia das cooperativas" (ACl, 2004).

O $5^{\circ}$ princípio defende que as cooperativas devem promover a educação e a formação de seus membros, dos representantes eleitos e dos trabalhadores, de modo que contribuam para o desenvolvimento da organização. $06^{\circ}$ princípio abarca a cooperação entre cooperativas, ao apontar a importância do trabalho conjunto, por meio de estruturas locais, regionais, nacionais e internacionais. $07^{\circ}$ princípio postula que os empreendimentos cooperativistas trabalham para a promoção do desenvolvimento sustentado de suas comunidades, através de políticas aprovadas pelos membros. Em sua análise, Cançado (2004) declara que: 
“Por serem organizações de pessoas e não de capital, as cooperativas possuem um espaço geográfico nítido, na medida em que estas pessoas residem em algum lugar. Quanto maior a cooperativa, menos se torna possível perceber este contorno, porém ele continua existindo. Neste sentido, quando as cooperativas passam a olhar para fora da própria organização, emerge uma noção de corresponsabilidade pelo espaço onde os cooperados habitam. Outra característica desta definição é a menção ao desenvolvimento sustentável, avesso ao assistencialismo e mais próximo de ações estruturantes" (CANÇADO, 2004, p. 36).

Para Cançado e Gontijo (2004) o êxito de Rochdale levou à expansão do cooperativismo pelo mundo. No Brasil, esse modo de produção chegou no século XX, inicialmente sob a forma de cooperativas de consumo (na cidade) e agropecuárias (no campo).

Nessa perspectiva, entende-se que as cooperativas não visam ao lucro, mas ao compromisso de melhorar as condições de vida dos associados. Pelo ideal educacional, social e econômico as cooperativas são capazes de gerar emprego e renda, bem como podem promover o acesso da sociedade a serviços como educação e saúde. Essas organizações possibilitam a inclusão socioeconômica, contribuem para a distribuição de renda e impulsionam o desenvolvimento local.

\subsection{Organização e relevância socioeconômica do cooperativismo no Brasil}

O cooperativismo produz impactos econômicos e sociais que melhoram as condições de vida de milhares de famílias pelo mundo. De acordo com os dados do 
Anuário do Cooperativismo Brasileiro (2019), existem aproximadamente 3 milhões de cooperativas. Juntas geraram cerca de 280 milhões de postos de trabalho.

No Brasil, as cooperativas estão distribuídas em sete ramos: agropecuário; consumo; crédito; infraestrutura; trabalho, produção de bens e serviços; saúde e transporte. É importante ressaltar que essa divisão em sete ramos é recente. Até 2019 a OCB, instituição responsável pelo registro das cooperativas, organizava as atividades em 13 ramos. Após debates, estudos e análises técnicas objetivando tornar os segmentos mais representativos, alguns ramos se fundiram, dando origem a uma nova organização, regulamentada pela Resolução OCB nº 56/2019.

Nessa nova configuração, as atividades cooperativistas passaram a ser caracterizadas conforme Quadro 3.

Quadro 3 - Reclassificação dos ramos do cooperativismo brasileiro

\begin{tabular}{|c|c|}
\hline $\begin{array}{l}\text { Ramos do } \\
\text { Cooperativismo }\end{array}$ & Composição \\
\hline 1 - Agropecuário & $\begin{array}{l}\text { Composto pelas cooperativas destinadas a prestação dos serviços } \\
\text { relacionados às atividades agropecuária, extrativista, agroindustrial, } \\
\text { aquícola ou pesqueira. Nessas cooperativas, os cooperados são detentores } \\
\text { dos meios de produção. }\end{array}$ \\
\hline 2 - Consumo & $\begin{array}{l}\text { Composto por cooperativas que se destinam a compra em comum de } \\
\text { produtos e/ou serviços para seus cooperados. }\end{array}$ \\
\hline 3 - Crédito & $\begin{array}{l}\text { Composto por cooperativas que promovem a prestação de serviços } \\
\text { financeiros a seus cooperados, sendo-lhes assegurado o acesso aos } \\
\text { instrumentos do mercado financeiro. }\end{array}$ \\
\hline 4 - Infraestrutura & $\begin{array}{l}\text { Composto por cooperativas destinadas a prestarem serviços relacionados } \\
\text { à infraestrutura a seus cooperados. }\end{array}$ \\
\hline $\begin{array}{l}5 \text { - Trabalho, } \\
\text { produção de bens } \\
\text { e serviços }\end{array}$ & $\begin{array}{l}\text { Composto por cooperativas que se destinam, a prestação de serviços } \\
\text { especializados a terceiros ou a produção em comum de bens. }\end{array}$ \\
\hline
\end{tabular}




\begin{tabular}{|l|l|}
\hline 6- Saúde & $\begin{array}{l}\text { Composto por cooperativas que promovem/adquirem serviços dedicados à } \\
\text { preservação, assistência e promoção da saúde humana, constituídas por } \\
\text { profissionais da área da saúde ou usuários destes serviços. }\end{array}$ \\
\hline 7 - Transporte & $\begin{array}{l}\text { Composto por cooperativas que se destinam, a prestação de serviços de } \\
\text { transporte de cargas e/ou passageiros, cujos cooperados detêm, a } \\
\text { qualquer título, a posse ou propriedade do(s) veículo(s). }\end{array}$ \\
\hline
\end{tabular}

Fonte: Fonte: OCB, 2019.

De acordo com o Anuário do Cooperativismo Brasileiro (2019), publicado pela OCB, no Brasil foram registradas 6.828 cooperativas no ano de 2018, com aproximadamente 14.618 .832 cooperados. Com base nas informações do Quadro 4 verifica-se que as cooperativas estão presentes em todos os estados brasileiros.

Uma análise da distribuição das cooperativas por unidades federativas mostra que São Paulo, Minas Gerais, Pará e Rio de Janeiro são os estados que mais possuem cooperativas registradas. Há uma concentração na região sudeste, fato explicado pelo expressivo número de cooperativas de crédito existentes nos estados dessa região. Apesar do Tocantins apresentar o menor quantitativo de cooperativas, observa-se que o número de cooperados é maior do que em outros estados como Sergipe, Acre, Amazonas, Amapá, Piauí, Alagoas e Roraima.

Quadro 4 - Distribuição das cooperativas e cooperados por Unidade Federativa

\begin{tabular}{|l|c|c|c|c|}
\hline Unidade Federativa & $\begin{array}{c}\text { Número de } \\
\text { cooperativas }\end{array}$ & Participação & $\begin{array}{c}\text { Número de } \\
\text { cooperados }\end{array}$ & Participação \\
\hline São Paulo & 1.025 & $15,0 \%$ & 3.093 .354 & $21,2 \%$ \\
\hline Minas Gerais & 771 & $11,3 \%$ & 1.738 .917 & $11,9 \%$ \\
\hline Pará & 541 & $7,9 \%$ & 95.867 & $0,7 \%$ \\
\hline Rio de Janeiro & 493 & $7,2 \%$ & 180.980 & $1,2 \%$ \\
\hline Rio Grande do Sul & 437 & $6,4 \%$ & 2.848 .481 & $19,5 \%$ \\
\hline Distrito Federal & 367 & $5,4 \%$ & 229.870 & $1,6 \%$ \\
\hline
\end{tabular}




\begin{tabular}{|l|c|c|c|c|}
\hline Pernambuco & 280 & $4,1 \%$ & 155.177 & $1,1 \%$ \\
\hline Santa Catarina & 258 & $3,8 \%$ & 2.460 .456 & $16,8 \%$ \\
\hline Goiás & 219 & $3,2 \%$ & 229.477 & $1,6 \%$ \\
\hline Paraná & 215 & $3,1 \%$ & 1.768 .253 & $12,1 \%$ \\
\hline Bahia & 205 & $3,0 \%$ & 163.505 & $1,1 \%$ \\
\hline Ceará & 169 & $2,5 \%$ & 75.168 & $0,5 \%$ \\
\hline Mato Grosso & 168 & $2,5 \%$ & 492.729 & $3,4 \%$ \\
\hline Amapá & 165 & $2,4 \%$ & 9.339 & $0,1 \%$ \\
\hline Paraíba & 163 & $2,4 \%$ & 58.972 & $0,4 \%$ \\
\hline Maranhão & 158 & $2,3 \%$ & 28.770 & $0,2 \%$ \\
\hline Rio Grande do Norte & 158 & $2,3 \%$ & 68.329 & $0,5 \%$ \\
\hline Espírito Santo & 149 & $2,2 \%$ & 444.147 & $3,0 \%$ \\
\hline Acre & 145 & $2,1 \%$ & 10.444 & $0,1 \%$ \\
\hline Rondônia & 129 & $1,9 \%$ & 132.018 & $0,9 \%$ \\
\hline Amazonas & 128 & $1,9 \%$ & 10.320 & $0,1 \%$ \\
\hline Roraima & 112 & $1,6 \%$ & 4.869 & $0,0 \%$ \\
\hline Mato Grosso do Sul & 111 & $1,6 \%$ & 261.157 & $1,8 \%$ \\
\hline Piauí & 87 & $1,3 \%$ & 9.200 & $0,1 \%$ \\
\hline Sergipe & 79 & $1,2 \%$ & 14.336 & $0,1 \%$ \\
\hline Alagoas & 6.828 & $1,0 \%$ & 6.691 & $0,0 \%$ \\
\hline Tocantins & $100,0 \%$ & 14.618 .832 & $100,0 \%$ \\
\hline Total & $11 \%$ & & $0,2 \%$ \\
\hline & 119.006 & & \\
\hline
\end{tabular}

Fonte: OCB, 2019.

No que diz respeito à distribuição por ramos, o cooperativismo no Brasil está presente principalmente nas atividades agropecuárias (23,6\%), seguidas de transporte $(19,8 \%)$, trabalho $(13,5 \%)$ e crédito $(13,5 \%)$. Essa realidade é comprovada pelas estatísticas do Censo Agropecuário do Instituto Brasileiro de Geografia e Estatística/IBGE de 2017, que mostram que cerca de $48 \%$ dos produtos oriundos do campo brasileiro passam, de alguma forma, por uma cooperativa. Logo, as cooperativas desses segmentos possuem expressiva relevância na economia do país, 
uma vez que, ao gerarem empregos, contribuem para o crescimento econômico e a melhoria do bem-estar de muitas comunidades brasileiras.

\subsection{A governança na gestão de cooperativas}

As organizações, de modo geral, precisam ser gerenciadas. Por meio da administração é possível planejar metas a serem alcançados, diagnosticar problemas e projetar cenários futuros. Nessa perspectiva, empreendimentos como as cooperativas não podem dispensar a gestão e o controle de seus recursos. Pelo contrário, para que uma cooperativa garanta bom funcionamento e possibilidades de crescimento é essencial que os cooperados sejam bem representados.

No atual contexto da globalização dos mercados, a boa gestão dos negócios é uma forma da cooperativa se manter e possivelmente crescer economicamente.

No que diz respeito às cooperativas, a Lei $n^{\circ} 5.764$ de 16 de dezembro de 1971 estabelece que serão administradas por um grupo de cooperados, eleitos pela "Assembleia Geral". Os membros desse grupo, chamado "Conselho de Administração", têm a função de direcionar as decisões no sentido de representar os interesses da cooperativa perante fornecedores, clientes, governos e outras instituições.

Tais gestores recebem a missão de administrar e tomar decisões que melhorem os resultados da cooperativa como um todo. Esse processo, que implica na determinação de responsabilidades, pode gerar custos relacionados à desconfiança e incerteza.

Em busca da sustentabilidade de seus empreendimentos, uma estratégia já adotada por empresas competitivas é a maior transparência na gestão dos recursos e prestação de contas dos resultados das ações administrativas. Isso significa que, no contexto atual, os proprietários estão atentos às ações de seus gestores. O propósito 
é avaliar se as decisões estão partindo dos interesses da organização ou se o gestor está agindo de maneira oportunista, em busca de seus interesses individuais.

Essa prática de acompanhamento e avaliação, chamada de governança, é relativamente recente. De acordo com o dicionário Michaelis (2020), a palavra governança vem do terno governar e refere-se à capacidade de monitoramento e avaliação do grupo de pessoas responsáveis pela administração dos recursos da organização. De outro modo, a governança é um mecanismo que revela como a empresa está sendo dirigida. Apesar de seu significado remeter à ideia de governo, é aplicável a todos os tipos de empreendimentos, como as cooperativas.

De acordo com o Instituto Brasileiro de Governança Corporativa//BGC ${ }^{1}$ (2020) a Governança Corporativa corresponde a "um conjunto de mecanismos e controles, internos e externos, que permitem aos cooperados definir e assegurar a execução dos objetivos da cooperativa, garantindo sua continuidade e os princípios cooperativistas". Nessa perspectiva, a governança consiste na elaboração e implementação de práticas que aprimorem o relacionamento entre os membros da organização, de modo a fortalecer a confiança.

A origem da governança remete a década de 1980, quando grandes investidores do mercado empresarial dos Estados Unidos passaram a questionar a forma de administração de certas organizações. O problema da falta de acompanhamento da atuação dos gestores foi o principal motivo para o surgimento desse modelo de gestão.

Depois do mercado empresarial americano, o movimento da governança se expandiu, chegou à Inglaterra e migrou para o resto da Europa. O contexto de difusão

\footnotetext{
${ }^{1}$ O Instituto Brasileiro de Governança Corporativa (IBGC), fundado em 27 de novembro de 1995, em São Paulo é uma organização sem fins lucrativos, de referência no Brasil e no mundo em governança corporativa. $\mathrm{O}$ instituto auxilia no desempenho sustentável das organizações através da produção e disseminação das melhores práticas em governança corporativa.
} 
do movimento das práticas de governança no Brasil foi marcado pela abertura do comércio nacional e privatizações em 1990, durante o governo Fernando Collor de Mello. Em 1995 foi criado o Instituto Brasileiro de Conselheiros de Administração/IBCA, que a partir de 1999 passou a se chamar Instituto Brasileiro de Governança Corporativa/IBGC. No mesmo ano foi lançado o primeiro documento com a finalidade de influenciar a adoção de práticas transparentes, equânimes e responsáveis. Trata-se do Código das Melhores Práticas de Governança Corporativa.

Segundo o IBGC (2015), a prática da boa governança baseia-se em 4 princípios: transparência, equidade, prestação de contas e responsabilidade corporativa. Esses princípios, que orientam o comportamento de sócios, gestores, conselhos e auditorias são os pilares os quais a governança está alicerçada.

Cada princípio básico da governança traduz uma recomendação ao fortalecimento das organizações, como mostra a Tabela 1.

Tabela 1 - Princípios da governança

\begin{tabular}{l|l}
\multicolumn{1}{c|}{ Princípio } & \multicolumn{1}{c}{ Caracterização } \\
\hline 1. Transparência & $\begin{array}{l}\text { Disponibilização de informações às partes interessadas. } \\
\text { Sem restrição de acesso }\end{array}$ \\
\hline 2. Equidade & $\begin{array}{l}\text { Tratamento justo e isonômico de todos os associados, } \\
\text { considerando direitos, deveres, necessidades, } \\
\text { expectativas e desejo. }\end{array}$ \\
\hline 3. Prestação de contas & $\begin{array}{l}\text { Apresentação da situação financeira (contas) e assumir as } \\
\text { consequências de atos e omissões }\end{array}$ \\
\hline 4. Responsabilidade \\
corporativa & Busca pela manutenção da organização no longo prazo \\
\hline
\end{tabular}

Fonte: IBGC, 2015. 
Apesar do conceito de governança ter surgido no ambiente das grandes empresas privadas, os princípios da governança podem ser aplicados a qualquer tipo de organização que deseje garantir os interesses dos membros e controlar o comportamento dos gestores.

Sendo assim, a adoção em cooperativas pode ser um caminho para a comunicação transparente, nutrindo a confiança entre os membros e impactando diretamente na gestão e no sucesso do empreendimento. Implantar tais princípios significa tornar a administração mais clara e atenta a possíveis erros e abusos que possam comprometer o desempenho da organização. A governança cooperativa, segundo a OCB (2020) corresponde a:

“... um modelo de direção estratégica, fundamentado nos valores e princípios cooperativistas, que estabelece práticas éticas visando garantir a consecução dos objetivos sociais e assegurar a gestão da cooperativa de modo sustentável em consonância com os interesses dos cooperados" (OCB, 2020, p. 13).

Bialoskorski Neto (2006) destaca que o cooperativismo vem enfrentando mudanças e as cooperativas precisam se mostrar abertas ao novo.

Para o IBGC (2020), o papel das práticas de governança na gestão de cooperativas tem como benefícios a otimização dos recursos, processos e tempo. A adoção dos princípios básicos preserva e amplia o valor econômico do empreendimento, fortalece o processo de decisão e contribui para a melhoria do desempenho da gestão.

Fontes Filho (2008) corrobora com a ideia ao defender que a criação de mecanismos e controles, internos e externos permitem aos cooperados definir e 
assegurar a execução dos objetivos das cooperativas, garantindo sua continuidade e os princípios cooperativistas.

Por fim, a adoção de práticas de governança tende a aprimorar a gestão e a fortalecer as relações de confiança entre relacionamento entre cooperados, administradores e funcionários, contribuindo assim para a redução de conflitos e riscos (IBGC, 2020).

\section{PROCEDIMENTO METODOLÓGICO}

Buscando atender aos objetivos propostos, esta é uma pesquisa explicativa, visto que se ocupou conhecer o processo de implantação de um modelo de governança num conjunto de cooperativas do ramo da saúde no Brasil e identificar o nível de práticas baseadas na transparência, equidade, prestação de contas e responsabilidade social.

Por meio de uma abordagem qualitativa esta investigação analisou, em profundidade, as informações apresentadas no estudo de caso prático realizado por Alves e D'Amario (2013), intitulado “Desafios para implantar um modelo de governança corporativa nas cooperativas da Unimed".

Apesar da rede da Unimed ser composta por 360 cooperativas, o estudo de Alves e D'Amario (2013) abarcou no ano de 2012 um total de 63 cooperativas e em 2013 foram 82. O trabalho das autoras não contemplou a totalidade das cooperativas da rede, pois investigou um plano de gestão que foi aderido por um pequena parcela.

Os resultados apresentados na sequência refletem características específicas, portanto, não permitem generalizações. 


\section{ANÁLISE DE RESULTADOS}

A Confederação Nacional das Cooperativas Médicas, ou simplesmente Unimed, foi criada em 1975. Atualmente é formada por 360 cooperativas de saúde, distribuídas em $84 \%$ do território brasileiro. Composta por médicos, dentistas e outros profissionais da saúde, esse conjunto de cooperativas oferece serviços de assistência médica e hospitalar a mais de 19 milhões de pessoas no Brasil.

De acordo com as informações coletadas no estudo realizado por Alves e D'Amario (2013), no ano de 2011, a Unimed identificou a necessidade de criar mecanismos capazes de tornar as cooperativas de sua rede mais transparentes, com maior credibilidade e sustentáveis no longo prazo.

Em busca de um caminho promissor, a presidência da Unimed propôs à sua rede de cooperativas a implantação de um modelo de gestão baseado na governança. Guiada pelo propósito de fortalecer as relações entre seus membros, alinhar os interesses dos envolvidos e melhorar o desempenho da gestão, desenvolveu um plano, denominado "Plano de Desenvolvimento Organizacional".

Os pilares utilizados na elaboração do Plano de Desenvolvimento Organizacional foram a transparência, a equidade, a prestação de contas e a responsabilidade corporativa, que são exatamente os princípios que regem as boas práticas da governança.

A primeira etapa do plano consistiu na criação de um prêmio, intitulado "Selo Nacional Unimed de Governança Cooperativista". A adoção do selo foi a maneira adotada pela Unimed para levantar informações sobre a gestão e avaliar o nível das práticas de governança nas cooperativas da rede. 
Apresentado às 360 cooperativas da rede Unimed, o propósito do prêmio residiu em estimular o aprimoramento da gestão. Para participar da premiação as cooperativas que aderissem voluntariamente ao instrumento seriam avaliadas em requisitos de governança.

Paralelamente, a presidência da Unimed produziu e distribuiu um manual com o propósito de apresentar, orientar e disseminar as práticas da governança. Nesse manual, foram considerados como boas práticas a participação, a direção estratégica, a gestão executiva, a fiscalização, o controle interno e externo. Cabe ressaltar que, nesse modelo, foram inseridas as propostas sugeridas pelo Instituto Brasileiro de Governança Corporativa.

Para obtenção do Selo, as cooperativas que aceitaram participar da premiação tiveram que responder a um questionário e preencher uma declaração de veracidade. Através desses documentos foram levantadas informações sobre as práticas das cooperativas.

Como critério de avaliação foram definidos três tipos de selo, com pontuações diferentes (ver Quadro 5).

Quadro 5 - Classificação das premiações do "Selo Nacional Unimed de Governança Cooperativista"

\begin{tabular}{|c|c|}
\hline Premiação & Pontuação \\
\hline $\begin{array}{l}\text { Selo } \\
\text { Diamante }\end{array}$ & Indica que a cooperativa segue todas as práticas de governança \\
\hline Selo Ouro & $\begin{array}{l}\text { Indica que a cooperativa pratica a governança, mas não totalmente } \\
\text { dentro dos padrões }\end{array}$ \\
\hline Selo Prata & Indica que a cooperativa pratica a governança, mas em estágio inicial \\
\hline
\end{tabular}

Fonte: Alves e D'Amario (2013). 
No ano de 2012 um total de 63 cooperativas participaram da avaliação e premiação. Em 2013 houve um aumento de 30\% na participação, com 82 cooperativas. O Quadro 6 apresenta os resultados das premiações.

Quadro 6 - Resultados das premiações do "Selo Nacional Unimed de Governança Cooperativista"

\section{Certificação}

\begin{tabular}{|l|c|c|}
\hline \multicolumn{1}{|c|}{ Certificação } & $\begin{array}{c}\text { Cooperativas } \\
\text { premiadas em 2012 }\end{array}$ & $\begin{array}{c}\text { Cooperativas } \\
\text { premiadas em 2013 }\end{array}$ \\
\hline Selo Diamante & 0 & 0 \\
Selo Ouro & 13 & 44 \\
Selo Prata & 19 & 27 \\
Não obtiveram Selo & 31 & 11 \\
\hline Total & $\mathbf{6 3}$ & $\mathbf{8 2}$ \\
\hline
\end{tabular}

Fonte: Alves e D'Amario (2013).

Observa-se que tanto na primeira quanto na segunda edição do plano não houve certificação com o "Selo Diamante", o que indica que nenhuma das cooperativas demonstrou seguir todas as práticas de governança. Porém, é inegável que houve uma melhoria nas cooperativas que obtiveram alguma certificação. Os dados do Quadro 6 apontam que de 2012 para 2013 houve uma queda no quantitativo de cooperativas que "Não obtiveram selo". Esse resultado sugere que as ideias defendidas pelo plano passaram a ser incorporadas por mais cooperativas.

Entre uma edição e outra da premiação foram realizadas oficinas temáticas nas cooperativas da Unimed com a finalidade de sensibilizar e incentivar a implementação de boas práticas de governança. A realização de tais oficinas baseouse na percepção de que à medida que as cooperativas possuíssem um melhor entendimento dos pilares da governança, maior seria a participação. 
Como resultado a participação aumentou de 17\% em 2012 para 22\% em 2013. Apesar do aumento, o percentual de participação em ambas as edições do prêmio foi baixo. Essas informações levam à seguinte indagação: se um dos princípios que regem o funcionamento das cooperativas é a participação, por que o pouco envolvimento e adesão das cooperativas ao Plano de Desenvolvimento Organizacional?

Convém ressaltar que essa não é uma realidade exclusiva da rede de cooperativas investigada nessa pesquisa. Albino e Almeida (2015) elencam que mesmo sendo controladas por todos os seus membros, a quantidade de cooperados que participam das decisões, dando ideias e sugestões e propondo mudanças é, de modo geral, pouca. Os autores trazem outra contribuição ao apontarem que quanto maior o quadro social, menor o envolvimento com os assuntos da organização.

O pouco envolvimento e a baixa participação dos cooperados tendem a uma concentração das decisões nas mãos dos dirigentes. Consequentemente enfraquecem o monitoramento e controle, abrindo espaço para comportamentos oportunistas e distanciando dos princípios do cooperativismo.

Sabe-se que os cooperados, por meio da Assembleia Geral, possuem o poder para tomar as decisões que julgarem convenientes. Mas só conseguirão realizar esse papel se estiverem munidos de informações sobre o andamento da organização, ou seja, se souberem como a empresa está sendo dirigida. Por isso a participação é tão relevante para as cooperativas que implantam práticas de governança.

É relevante lembrar que as práticas de monitoramento, controle e divulgação de informações surgiram exatamente para reduzir a incerteza sobre a condução dos negócios e evitar conflitos de interesse. Jensen e Mecking (1976), sustentam que os dirigentes tendem a se guiar pela maximização de seus próprios benefícios e não de 
acordo com os objetivos da organização e das partes interessadas. E quando as decisões representam vantagens individuais, e não coletivas, estabelece-se um conflito de interesses.

Tendemos a concordar com Fontes Filho et al (2008) que a participação, tão necessária à governança é também o elemento principal para a sustentação de uma cooperativa. Se as cooperativas, por meio de seus cooperados, não praticam a participação torna-se difícil implantar a transparência, a equidade, a prestação de contas e a responsabilidade corporativa.

As constatações apresentadas nessa pesquisa evidenciam a necessidade de intensificar a sensibilização das cooperativas da rede Unimed para a importância de participarem ativamente do processo de implantação de novas práticas de gestão. 0 incentivo à interação entre cooperados, conselhos, diretorias e auditorias é um bom caminho para avigorar a confiança.

Acredita-se que se os membros estiverem envolvidos saberão o que está acontecendo na cooperativa e se sentirão responsáveis pelas decisões. Desse modo as chances de sobrevivência da organização são grandes.

Fortalecer a participação é possível? Sim, no entanto trata-se de um processo gradual, que perpassa por uma mudança de mentalidade e comportamento. Santos e Barreto (2017) acreditam que uma maneira de motivar os cooperados a participarem está na contrapartida de benefícios, ou seja, o cooperado estará disposto a se envolver com os problemas se perceber que terá uma recompensa.

Os resultados da pesquisa trouxeram outras informações importantes referentes aos quesitos definidos pelo regulamento da premiação para avaliação das práticas de governança nas cooperativas. Observa-se no Quadro 7 que as cooperativas participantes da premiação "Selo Nacional Unimed de Governança 
Cooperativista" mostraram atender requisitos como: auditoria independente, código de conduta, reuniões e relatórios de gestão, planejamento estratégico e divulgação das boas práticas de governança.

Desse modo, tende-se a afirmar que as cooperativas avaliadas, ao disponibilizarem informações sobre a gestão e permitirem que profissionais externos avaliem suas demonstrações contábeis, têm se esforçado a seguir o princípio da transparência. No entanto, as informações disponibilizadas se restringem ao desempenho econômico-financeiro. O ideal é que contemplem outros fatores que auxiliem a preservação do valor da organização.

Inclusive, as instruções do Instituto Brasileiro de Governança Corporativa/IBGC, por meio do Código das Boas Práticas de Governança Corporativa (2019), convergem para a ampliação da transparência da administração para a sociedade cooperativa.

Sabe-se que as cooperativas não são obrigadas a serem transparentes em todos os seus atos. Porém, a experiência tem mostrado que a prática da transparência nas ações induz a confiança entre os próprios cooperados e os incentiva a participar. Em seus estudos, Lorsch (2012) concluiu que quando os dirigentes das cooperativas divulgam informações que demonstram suas ações e resultados econômicos e sociais, o ambiente torna-se mais confiável.

Por outro lado, as informações deixam claro que existem determinados quesitos que precisam ser melhor trabalhados. São eles: ouvidoria, avaliação de desempenho, programa de desenvolvimento de conselheiros, auditoria interna, pesquisa para reajustes salarias e gestão por competências, como mostram os percentuais de atendimento aos quesitos, apresentados no Quadro 7. 
Quadro 7 - Quesitos utilizados para avaliação das práticas de governança

\begin{tabular}{|l|c|}
\hline \multicolumn{1}{|c|}{ Quesitos } & $\begin{array}{c}\text { Percentual } \\
\text { de }\end{array}$ \\
\hline Auditoria independente & atendimento \\
Existência de Código de Conduta & $98 \%$ \\
Respeito à atuação estatutária & $97 \%$ \\
Elaboração de relatórios periódicos de gestão & $97 \%$ \\
Realização de reuniões periódicas de gestão & $88 \%$ \\
Existência de planejamento estratégico & $85 \%$ \\
Divulgação de informações sobre governança & $76 \%$ \\
Política de admissão de cooperados & $72 \%$ \\
Ouvidoria & $71 \%$ \\
Avaliação de desempenho & $66 \%$ \\
Existência de programa de desenvolvimento de conselheiros & $45 \%$ \\
Cumprimento dos requisitos mínimos para a atuação de dirigentes e & $42 \%$ \\
conselheiros & $41 \%$ \\
Auditoria interna & \\
Existência de Comitê de Recursos Humanos & $35 \%$ \\
Pesquisa de cargos e salários para fins de reajustes de pró-labore & $17 \%$ \\
Gestão por competência para os dirigentes & $16 \%$ \\
\hline
\end{tabular}

Fonte: Alves e D'Amario (2013).

Nota-se que $66 \%$ das cooperativas participantes implantaram um setor específico para ouvir seus clientes. A ouvidoria é um instrumento que avalia o serviço prestado e a satisfação dos usuários. Por isso, para seguir nos caminhos da boa governança é fundamental que as cooperativas tenham um setor específico para tal finalidade.

Em relação à avaliação de desempenho, 45\%, ou seja, menos da metade das cooperativas a realizam. Para que a governança aconteça é necessário avaliar se o 
Conselho de está protegendo o patrimônio e buscando maximizar o retorno. Assim será possível identificar se os dirigentes estão realizando uma gestão justa e sustentável.

Vê-se também no Quadro 7 que $42 \%$ das cooperativas participantes da premiação realizam a capacitação de seus conselheiros, o que reflete diretamente no cumprimento das funções estratégicas. Esse percentual é baixo, ainda mais se considerando a baixa adesão das cooperativas da rede Unimed ao plano.

Se a administração não possui conselheiros preparados, estes não conseguirão elaborar planos de contingência, zelar pelo código de conduta, realizar a gestão de risco, entre outros. A preocupação com a educação e formação dos dirigentes e cooperados é um princípio cooperativista que está atrelado à responsabilidade social.

Quanto à auditoria interna, apenas 35\% das cooperativas a realizam, o que deixa claro a necessidade de criação de um comitê que analise se as ações estão alinhadas com os objetivos.

Em relação à gestão por competência, observa-se que é o quesito menos praticado pelas cooperativas participantes. Por meio da gestão por competências é que se identifica os conhecimentos, habilidades e atitudes de um dirigente para gerir uma cooperativa, assim como as lacunas que podem impactar negativamente no desempenho e prejudicar os interesses coletivos. Por isso merece mais atenção.

Apesar do estudo não apresentar dados assertivos, os resultados nos leva a acreditar que a resistência à inovação por parte dos dirigentes pode ser outro percalço que influencia diretamente na prestação de contas e na responsabilidade corporativa. 
A governança é um modelo de gestão recente, que chegou com a globalização econômica, mas tem mostrado ser um caminho no sentido da inovação e melhoria da competitividade. Tanto que a produção científica sobre governança em cooperativas é escassa, o que abre oportunidades para novas descobertas (BAGGIO et al, 2019).

Além da transparência, prestação de contas e responsabilidade corporativa, a governança nas cooperativas requer a equidade. Os resultados referentes à participação nos leva a inferir que a isonomia e o tratamento justo não é um princípio satisfatoriamente adotado por todas as cooperativas da rede.

Essa realidade é defendida por Esteves (2003) como algo constante nas cooperativas, pois de um lado tem-se os conselheiros e do outro, os demais cooperados. Nas palavras do autor "Quando isto ocorre dá-se ou torna-se evidente uma ou diversas cisões no grupo, revelando a todos a existência de dois ou mais grupos de interesses distintos, não apenas diferentes, mas desiguais e contraditórios, isolados por uma barreira invisível e aparentemente insuperável". Logo, a suposta hierarquia reflete no poder sobre as decisões e cria uma situação que inibe a gestão democrática.

Os resultados apresentados nos permite pontuar que a implantação das práticas da governança em $22 \%$ das cooperativas da rede Unimed não alcançou resultados tão satisfatórios, quando se considera como critérios a adoção de práticas de transparência, equidade, prestação de contas e responsabilidade corporativa.

Colocar em prática novos modelos de gestão não é uma tarefa fácil. Como exposto, é recente a criação da governança, por isso suas práticas ainda estão pouco disseminadas nas organizações. E quando essa implantação acontece no âmbito das cooperativas, torna-se mais complexo, pois envolve o alinhamento dos interesses de todos os cooperados e não apenas de um pequeno grupo de proprietários. 
Defendemos que o plano desenvolvido pela Unimed em 2011 foi um marco para a introdução dos ideais da governança nas cooperativas da rede. Em 2015 a Unimed Rio passou a divulgar abertamente seus relatórios para assegura a transparência e garantir que não houvessem conflitos de interesse. Em 2017 a Unimed Chapecó elaborou seu próprio manual para consolidação das normas voltadas às melhores práticas de governança. Em 2019 a Unimed João Pessoa criou uma política de governança corporativa visando adequar à conduta dos de seus conselhos, diretorias e assembleia. Esses são alguns exemplos.

O objeto dessa investigação restringiu-se ao modelo implantado nos anos de 2012 e 2013. De lá pra cá as práticas da governança evoluíram e foram ganhando espaços num número cada vez maior de cooperativas da Unimed.

Atualmente, a premiação ganhou nova roupagem. O Selo Nacional Unimed de Governança Cooperativista passou a se chamar Selo Unimed de Governança e Sustentabilidade. As categorias de certificação foram ampliadas para Diamante, Ouro, Prata e Bronze. Essas mudanças sugerem que a rede permanece empenhada em consolidar as boas práticas de governança em suas cooperativas.

\section{CONSIDERAÇÕES FINAIS}

No Brasil, as cooperativas possuem um papel socioeconômico relevante. Por isso, a preocupação com a sustentabilidade dessas organizações motiva o desenvolvimento de investigações que busquem apontar as fragilidades que tendem a comprometer o desempenho das cooperativas.

Esta pesquisa, ao analisar o processo de implantação do Plano de Desenvolvimento Organizacional nas cooperativas da rede Unimed, por meio do "Selo Nacional Unimed de Governança Cooperativista", nos anos de 2012 e 2013, mostrou 
que as cooperativas participantes podem ser enquadradas num nível inicial de consolidação das práticas de governança.

A adesão de apenas 17\% das cooperativas em 2012 e 22\% em 2013 mostra que há certo desinteresse na gestão. O baixo envolvimento e participação das cooperativas no plano de modernização da gestão é complementado pela existência de poucas práticas sustentadas na transparência, equidade, prestação de contas e responsabilidade corporativa.

Esse desinteresse abre espaço para a concentração do poder e decisões, restrição das informações econômico-financeiras ao grupo gestor, resistência à inovação e autoavaliação, entre outros que podem aumentar a desconfiança entre os cooperados e gerar conflitos de interesses. Esse desencadeamento de ações é prejudicial para a sustentabilidade da organização.

Pelo exposto, considera-se que, nas cooperativas da Unimed, existem lacunas que precisam ser preenchidas para que o modelo de governança seja aprimorado. No entanto, acredita-se que essa iniciativa, mesmo não apresentando os resultados mais satisfatórios, representa um avanço que tende a fortalecer a organização como um todo.

Acredita-se ser possível fortalecer as práticas da governança. A aprimoração é um processo contínuo, que requer sensibilização, maior envolvimento e entendimento dos pilares que sustentam as boas práticas de governança. Sugere-se também esforços no sentido de dar mais visibilidade à gestão dos recursos e investir na formação de dirigentes e conselheiros para que aperfeiçoem seus conhecimentos e desempenhem bem suas funções.

Os levantamentos e diagnósticos deste estudo servem como referência para que outras cooperativas desenhem caminhos de gestão que reforcem as ideias de 
solidariedade, democracia e autonomia e fortaleçam o relacionamento entre seus cooperadores e aumentem a confiança dos clientes.

Esta pesquisa não esgota as discussões sobre a implantação de modelos de governança em cooperativas de saúde, pelo contrário, por trazer uma abordagem específica instiga o desenvolvimento de novas análises que explorem os mecanismos da governança e ampliem suas possibilidades de beneficiar os cooperados e fortalecer a organização.

\section{REFERÊNCIAS}

ABRANTES, José. Associativismo e cooperativismo: como a união de pequenos empreendedores pode gerar emprego e renda no Brasil. Rio de janeiro: Interciência, 2004.

ALBINO, Pablo Murta Baião; ALMEIDA, Hugo Francisco. A falta de participação como fator limitando ao desenvolvimento das organizações cooperativas. Revista de Gestão e Organizações Cooperativas: Santa Maria, 2015.

ALVES, Ana Lúcia Dominguez; D'AMARIO, Jânia Evangelista. Desafios para implantar um modelo de governança corporativa nas cooperativas da Unimed. São Paulo, 2013.

BAGGIO, Adelar Francisco; BAGGIO, Daniel Knebel; KELM, Martinho Luis. Desafios, experiências e estratégias de adoção da governança em cooperativas. Revista da Universidade Vale do Rio Verde: 2019. Disponível em: file:///C:/Users/Bruna/Downloads/5084-10953178-1-PB.pdf Acesso em 29 mar 2020.

BIALOSKORSKI NETO, Sigismundo. Aspectos econômicos das cooperativas. Belo Horizonte: Mandamentos, 2006.

BRASIL. Lei $n^{\circ}$ 5.764, de 16 de dezembro de 1971. Define a Política Nacional de Cooperativismo, institui o regime jurídico das sociedades cooperativas, e dá outras 
providências. Disponível em http://www.planalto.gov.br/ccivil_03/LEIS/L5764.htm Acesso em 03 abril 2020.

CANÇADO, Airton Cardoso. Autogestão em cooperativas populares. Dissertação (Mestrado em Administração - Universidade Federal da Bahia. Salvador, p. 134, 2004.

CANÇADO, Airton Cardoso; GONTIJO, Mário César Hamdan. Princípios cooperativistas: origem, evolução e influência na legislação brasileira. In: ENCONTRO DE INVESTIGADORES LATINOAMERICANO DE COOPERATIVISMO, 2004.

CARDOSO, Rosinaldo Nunes; CASTAGNA, Michele Caroline. Governança corporativa: princípios e práticas em uma cooperativa de saúde. Santa Maria/RS: Revista de Gestão e Organizações Cooperativas - RGC, Vol. 6, n¹1, jan./jun. 2019.

CRISTOFOLINI, A. Tratamento tributário do ato cooperativo. Rio de Janeiro: Lumen Juris, 2014.

ESTEVES, Egeu Gomes. Os desafios à igualdade nas cooperativas autogestionárias. São Paulo, 2015.

FONTES FILHO, Joaquim Rubens. Governança corporativa: principais conceitos e aplicações às cooperativas. Brasília: Bacen, 2008.

FONTES FILHO, Joaquim Rubens; VENTURA, Elvira Cruvinel Ferreira; OLIVEIRA, Mauro José de. Governança e participação no contexto das cooperativas de crédito. Belo Horizonte: Faces Revista de Administração, 2008. Disponível em file:///C:/Users/Bruna/Downloads/123-126-1-PB.pdf Acesso em 03 abril 2020.

GIL, Antônio Carlos. Métodos e técnicas de pesquisa social. São Paulo: Atlas, 2008.

HOLYOAKE, George Jacob. Os 28 tecelões de Rochdale. 9. ed. Porto Alegre: WS Editor, 2005.

IBGE. Censo agropecuário 2017: resultados definitivos. Rio de Janeiro, 2019. 
IBGC. Código das melhores práticas de governança corporativa. São Paulo: IGGC, 2015. IBGC. O que é governança corporativa. Disponível em: https://www.ibgc.org.br/conhecimento/governanca-corporativa Acesso em 03 abril 2020.

JENSEN M. e MECKLING, W. Theory of the firm: Managerial behavior, agency cost, and ownership structure. In: Journal os Financial Economics. 1976.

LORSCH, Jay William. The future of boards: meeting the governance challenges of the twentyfirst century. Harvard Business Press, 2012.

MARX, Karl. O Capital. Vol. 2. $3^{a}$ edição. São Paulo: Nova Cultural, 1988.

MENDES, Simoni Morobosi; HERNANDES, Tatiani Fernanda Pereira; SILVA, Ademir da. Principais causas de insucesso e fechamento de cooperativas. Revista Organização e Sociedade: Iturama/MG, 2015.

OCB. Anuário do Cooperativismo Brasileiro. Brasília, 2019. Disponível em http://www.paranacooperativo.coop.br/ppc/images/Comunicacao/2019/noticias/07/0 4/publicacao/publicacao_clique_aqui_04_07_2019.pdf Acesso em 02 fev 2020.

OCB. Manual de boas práticas de governança cooperativa, 2020. Disponível em http://www.ocesc.org.br/documentos/manual_boas_praticas.pdf Acesso em 02 fev 2020.

OCB - Organização das Cooperativas Brasileiras. História do Cooperativismo, 2020. Disponível em: https://www.ocb.org.br/historia-do-cooperativismo Acesso em 07 fev 2020.

OCB - Organização das Cooperativas Brasileiras. Ramos do Cooperativismo, 2019. Disponível em: file:///C:/Users/Bruna/Downloads/Cartilha_Ramos_2019\%20(1).pdf Acesso em 20 jul 2020. 
OCB - Organização das Cooperativas Brasileiras. Quais as principais diferenças entre um empreendimento cooperativo e uma empresa não cooperativa? 2020.

PINHO, Diva Benevindes. O cooperativismo no Brasil: da vertente pioneira à vertente solidária. São Paulo: Saraiva, 2004.

SESCOOP. Disseminação de práticas: o modelo cooperativista. Disponível em http://www2.fnq.org.br/PAINEL_B_apresentacao_SESCOOP1.pdf Acesso em 24 mar 2020.

SANTOS, Ana Paula Oliveira; BARRETO, Raquel de Oliveira. Fatores de insucesso para a construção e sustentabilidade de cooperativas de produção: o caso da cooperativa Cachaçaboa de Araguaí-MG. 2017; Trabalho de Conclusão de Curso; (Graduação em Administração) - Instituto Federal de Educação Ciência e Tecnologia do Norte de Minas Gerais.

SINGER, Paul. Introdução à economia solidária. São Paulo: Editora Fundação Perseu Abramo, 2002. 
